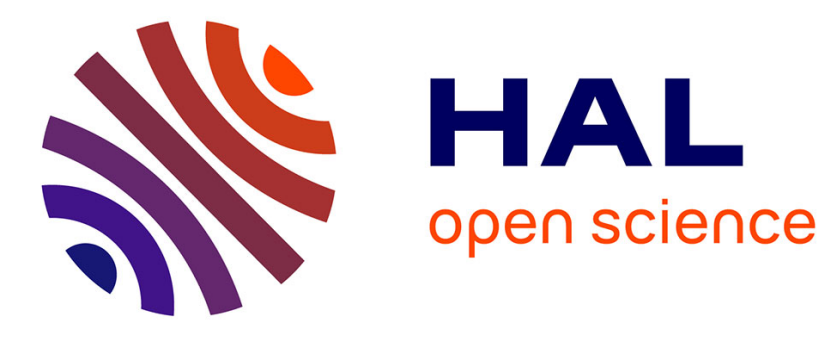

\title{
Reduction of EMI using Anticontrol of Chaos
}

\author{
Marcelle Merhy, Cristina Morel, Eric Chauveau, Mohamed Machmoum
}

\section{To cite this version:}

Marcelle Merhy, Cristina Morel, Eric Chauveau, Mohamed Machmoum. Reduction of EMI using Anticontrol of Chaos. 10th International Conference on Environment and Electrical Engineering, EEEIC.EU 2011, May 2011, Rome, Italy. 10.1109/EEEIC.2011.5874793 hal-01407674

\section{HAL Id: hal-01407674 https://hal.science/hal-01407674}

Submitted on 23 Feb 2018

HAL is a multi-disciplinary open access archive for the deposit and dissemination of scientific research documents, whether they are published or not. The documents may come from teaching and research institutions in France or abroad, or from public or private research centers.
L'archive ouverte pluridisciplinaire $\mathbf{H A L}$, est destinée au dépôt et à la diffusion de documents scientifiques de niveau recherche, publiés ou non, émanant des établissements d'enseignement et de recherche français ou étrangers, des laboratoires publics ou privés. 


\section{Reduction of EMI using anticontrol of chaos}

\author{
Marcelle Merhy, Cristina Morel, Eric Chauveau \\ Département Automatismes et informatique inclus \\ ESEO, Grande Ecole d’Ingénieurs Généralistes \\ 4 rue Merlet de la Boulaye BP 30926, \\ 49009 Angers Cedex 01-France \\ marcelle.merhy@eseo.fr
}

\author{
Mohamed Machmoum \\ Département Génie Electrique \\ IREENA, Institut de recherche en Electronique et \\ Electrotechnique de Nantes Atlantique \\ 37 Boulevard de l'université BP 406, \\ 44602 Saint-Nazaire France
}

\begin{abstract}
DC-DC converters are employed in various electrical devices, thus forming main sources of electromagnetic interference (EMI). By making the DC-DC converter operating in chaos, using a new nonlinear feedback controller, the simulation results illustrate that a reduction of spectral peak and consequent spreading of the spectrum can be shown. This simple strategy not only improves the electromagnetic compatibility of the converter, but also reduces the output voltage ripple. A Power System Blockset (PSB) model using Simulink/Matlab is designed and results are compared to those obtained with the classical anticontrol method.
\end{abstract}

Keywords-Buck converter; electromagnetic interference (EMI); electromagnetic compatibility (EMC); chaos; anticontrol; PSB Simulink/Matlab.

\section{INTRODUCTION}

Switched mode DC-DC converters are the most popular power supply in industrial products. However, it was found to have large electromagnetic interference (EMI) due to the rapid switching of high currents and voltages, generally consisting of the switching frequency and many harmonics. This EMI give rise to important electromagnetic compatibility (EMC) problems. Nowadays, switched mode power supplies have to be designed not only to provide the required electrical functions, but also to meet international EMC standards.

Traditionally, the principal method in power converter EMI suppressing has been passive noise filtering for conducted EMI and metal shielding for radiated EMI [1]. Another approach that modulates the switching frequency has been proposed to reduce the spectral emissions [2][3]. Besides increasing the size, weight, a more important problem is a large extra waste of money in manufacturing cost. Such a design is not portable across different EMC norms because each time application domain changes, filters have to be redesigned and manufactured for each application even if the converter specifications themselves are unchanged.

Recently, the study and its possible application of chaos, a nonlinear phenomenon which may occur naturally in switchmode power supplies when some of the system parameter get changed, have been an active subject. Most power electronic engineers try to avoid this mode of operation by choosing such component values that will give periodic ripples in the voltage and current waveforms. The work of Hamill and Deane [4] argued against such practice and proved that chaos might be used to improve EMC switch-mode power supplies without any additional circuitry. Thus, the periodicity of the converter voltages and currents is disrupted so that the energy of the interfering signal that was originally concentrated at the harmonic frequency is spread over a large bandwidth with a consequent reduction of the peak value in the power density spectrum of the interfering signals emitted by the system. However, [5] reported some inherent problems of chaotic operation like increased ripple and higher emissions floor.

The task of making a nonchaotic dynamical system known as "chaotication" (or sometimes, "anticontrol"), has attracted more and more attention from the engineering and physics communities in recent years due its great potential in nontraditional applications for physical, electrical, optical, mechanical, chemical, biological, and medical systems[6][7].

The anticontrol method designs a nonlinear feedback controller with an arbitrarily small amplitude [8][9][10], thus obtaining chaotic dynamics in the controlled system. The application of this method [8][10] to switch-mode power supplies reduces the output voltage spectral emissions, but aggravates the overall magnitude of the ripple [11]. The work of [11] introduces a nonlinear feedback controller that maintains a small ripple in the output and also achieves a low spectral emission. A new nonlinear feedback controller is introduced in [12], much simpler that in [11], and with better performance. The initial nonlinear system is chaotified using a simple sine function of the system state, as in [10], but with large amplitude.

Although the earlier measurements have been done at low frequency $(2.5 \mathrm{kHz})$, the results should scale to higher frequency for practical power supplies. Also, only numeric analysis method is used to simulate the results.

In this paper, a Power System Blockset (PSB) model using Simulink/Matlab is designed for a DC-DC buck converter choosing a higher frequency value $(50 \mathrm{kHz})$ and using the new method proposed in [12], which includes a comparison with the classical anticontrol method. Results illustrate that this method can improve the converter in time domain (ripple) and frequency domain (spectrum). 


\section{OPERATION OF THE VOLTAGE-CONTROLLED BUCK CONVERTER}

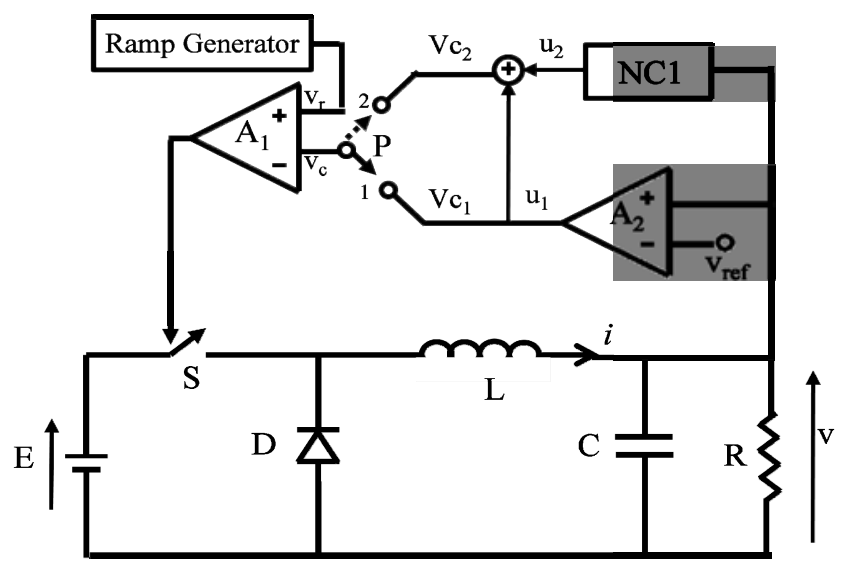

Figure 1. DC-DC Buck converter with feedback anticontrol.

The buck converter consists of a switch $\mathrm{S}$ which is controlled by a pulse-width modulated signal to achieve the required output. The block diagram of voltage controlled Buck converter is shown in fig. 1 and the converter is assumed to operate in continuous conduction mode (CCM), so the inductor current never falls to zero. The circuit has two switch states, according to the position of the switch S. When $\mathrm{S}$ is closed, the input voltage $E$ provides energy to the load $R$ as well as to the inductor L. When S is open, the inductor current $\mathrm{i}$, which flows through diode $\mathrm{D}$, transfers some of its stored energy to the load $\mathrm{R}$. The amplifier $\mathrm{A}_{2}$ has a gain a. The simplest feedback converter is obtained when the switch $\mathrm{P}$ in the first position. The difference between the output voltage $\mathrm{v}(\mathrm{t})$ and the reference voltage $\mathrm{V}_{\text {ref }}$ is amplified so that the resultant control voltage $\mathrm{v}_{\mathrm{C}}(\mathrm{t})$ is

$$
\mathrm{v}_{\mathrm{c}}(\mathrm{t})=\mathrm{v}_{\mathrm{c} 1}(\mathrm{t})=\mathrm{u}_{1}(\mathrm{t})=\mathrm{a}\left(\mathrm{v}(\mathrm{t})-\mathrm{V}_{\text {ref }}\right)
$$

This voltage is applied to the inverting input of the comparator $A_{1}$ and then compared with the ramp voltage given by

$$
\mathrm{V}_{\mathrm{r}}(\mathrm{t})=\mathrm{V}_{\mathrm{L}}+\left(\mathrm{V}_{\mathrm{U}}-\mathrm{V}_{\mathrm{L}}\right) \frac{\mathrm{tmodT}}{\mathrm{T}}
$$

Where $\mathrm{V}_{\mathrm{L}}$ and $\mathrm{V}_{\mathrm{U}}$ are respectively the lower and upper voltages of the ramp and $\mathrm{T}$ is period.

When $\mathrm{v}_{\mathrm{c}}(\mathrm{t}) \geq \mathrm{v}_{\mathrm{r}}(\mathrm{t})$, the switch $\mathrm{S}$ is open and diode $\mathrm{D}$ conducts; Otherwise $\mathrm{S}$ is closed and $\mathrm{D}$ is blocked. The converter is governed by two sets of linear differential equations that correspond to the on and off states of the controlled switch written as:

S Closed when $\mathrm{v}_{\mathrm{c}}(\mathrm{t}) \geq \mathrm{v}_{\mathrm{r}}(\mathrm{t})$ :

$$
\begin{gathered}
\frac{\mathrm{dv}}{\mathrm{dt}}=\frac{1}{\mathrm{C}} \mathrm{i}(\mathrm{t})-\frac{1}{\mathrm{RC}} \mathrm{v}(\mathrm{t}) \\
\frac{\mathrm{di}}{\mathrm{dt}}=-\frac{1}{\mathrm{~L}} \mathrm{v}(\mathrm{t})+\frac{\mathrm{E}}{\mathrm{L}}
\end{gathered}
$$

S Open when $v_{c}(t) \leq v_{r}(t)$ :

$$
\begin{gathered}
\frac{\mathrm{dv}}{\mathrm{dt}}=\frac{1}{\mathrm{C}} \mathrm{i}(\mathrm{t})-\frac{1}{\mathrm{RC}} \mathrm{v}(\mathrm{t}) \\
\frac{\mathrm{di}}{\mathrm{dt}}=-\frac{1}{\mathrm{~L}} \mathrm{v}(\mathrm{t})
\end{gathered}
$$

Where $\mathrm{E}$ is a constant input voltage, $\mathrm{v}$ is the voltage through the capacitor and $\mathrm{i}$ is the current in the inductor.

\section{GENERATING CHAOS}

By using a state feedback control with a small magnitude, the converter works on intermittent chaos [8][10]. The feedback control in [8] and [9] is a simple sinusoidal function of the system state. This anticontrol method considers the use of an additional nonlinear feedback controller NC1, ie, with switch P of fig. 1 in position 2. The application of this method to switch-mode power supplies leads to a chaotic output voltage $\mathrm{v}(\mathrm{t})$. Work [12] presents a new control law that expressed as:

$$
\mathrm{v}_{\mathrm{c}}(\mathrm{t})=\mathrm{vc}_{2}(\mathrm{t})=\mathrm{u}_{1}(\mathrm{t})+\mathrm{u}_{2}(\mathrm{t})
$$

Where

$$
\mathrm{u}_{2}(\mathrm{t})=\mathrm{c}_{2} \sin \left[\mathrm{w}_{2}\left(\mathrm{v}(\mathrm{t})-\mathrm{V}_{\text {ref }}\right)\right]
$$

In order to illustrate the efficiency of this method, a PSB model is designed in fig. 2 with the following values: $L=4$ $\mathrm{mH}, \mathrm{C}=22 \mu \mathrm{F}, \mathrm{R}=22 \Omega, \mathrm{a}=8.4, \mathrm{~V}_{\text {ref }}=150 \mathrm{~V}, \mathrm{~V}_{\mathrm{L}}=3.8 \mathrm{~V}, \mathrm{~V}_{\mathrm{U}}$ $=8.4 \mathrm{~V}, \mathrm{~T}=20 \mu \mathrm{s}, \mathrm{E}=220 \mathrm{~V}$.

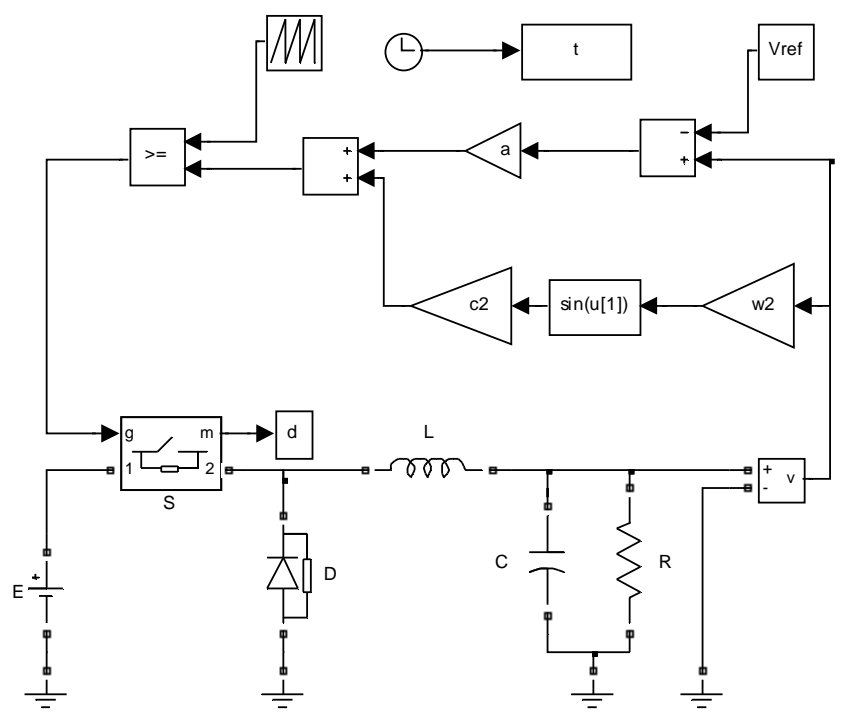

Figure. 2 Scheme of the PSB Model of the buck converter with feedback anticontrol.

When the coefficient $c_{2}$ of the disturbing signal varies, the converter can display complex nonlinear phenomena. 
While the coefficient $c_{2}$ is 0 , thus the converter is governed by the control law $\mathrm{v}_{\mathrm{c} 1}(\mathrm{t})$ of $(1)$, the converter works on usual PWM mode.

Fig. 3 illustrates the output voltage of the converter on periodic state with a $27 \mathrm{mV}$ ripple. The spectrum of the output voltage $v(t)$ is shown in fig. 4, the energy concentrate on switching frequency and its harmonics, the peak values are relatively high and the EMC rulers are not easy to meet. So, let us try to reduce the peak value of the spectrum while maintaining a small ripple.

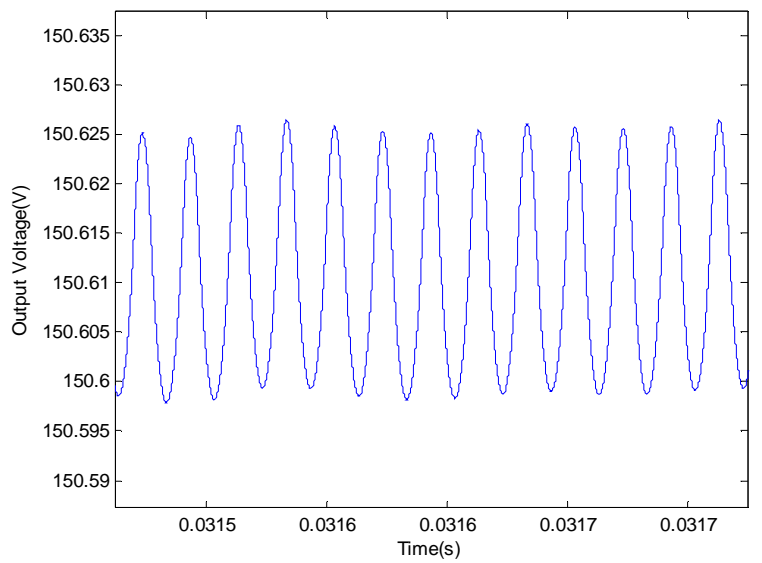

Figure. 3 Periodic output voltage $v(t)$ of the buck converter with the law control $\mathrm{v}_{\mathrm{c} 1}(\mathrm{t})$ of (1) (27 $\mathrm{mV}$ ripple).

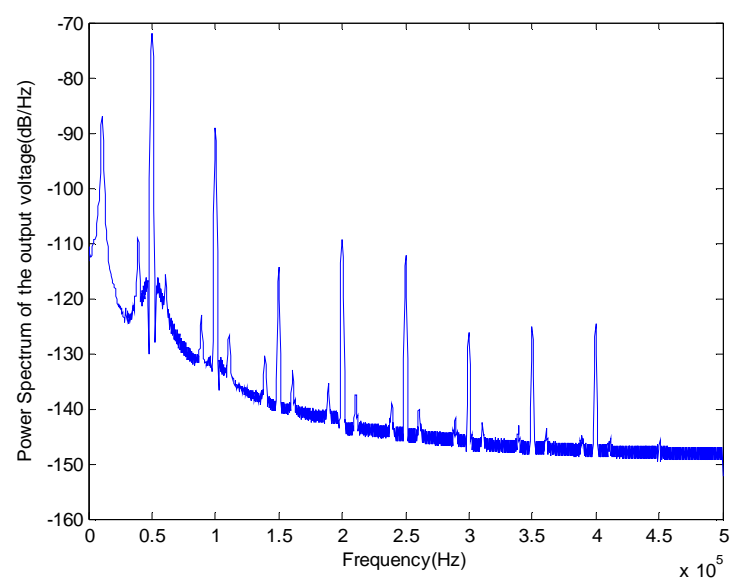

Figure. 4 Power spectrum of the output voltage $v(t)$ with the law control $v_{\mathrm{c} 1}(t)$ of (1).

Fig. 5 and fig. 6 show the chaotic output voltage v(t) and the power spectrum respectively when the converter is governed by the control law $\mathrm{v}_{\mathrm{c} 2}(\mathrm{t})$ of (5) obtained with $\mathrm{c}_{2}=8$ and $\mathrm{w} 2=300 \mathrm{rad} / \mathrm{V}$.

Compared the spectrum of periodic state with that chaotic state, the spectrum of chaotic state spreads to wider range, the peak at the switching frequency $1 / \mathrm{T}$ (or at its harmonics) is drastically reduced. Average reduction at the switching frequency and its harmonics is at least $35 \mathrm{~dB}$. The small amplitude of the parameters $\mathrm{c}_{2}$ as in [8] leads to the conclusion that, unfortunately, the time domain performance is worsened because the output voltage ripple has increased $(380 \mathrm{mV}$ ripple), thus reducing the efficiency of the DC-DC converter.

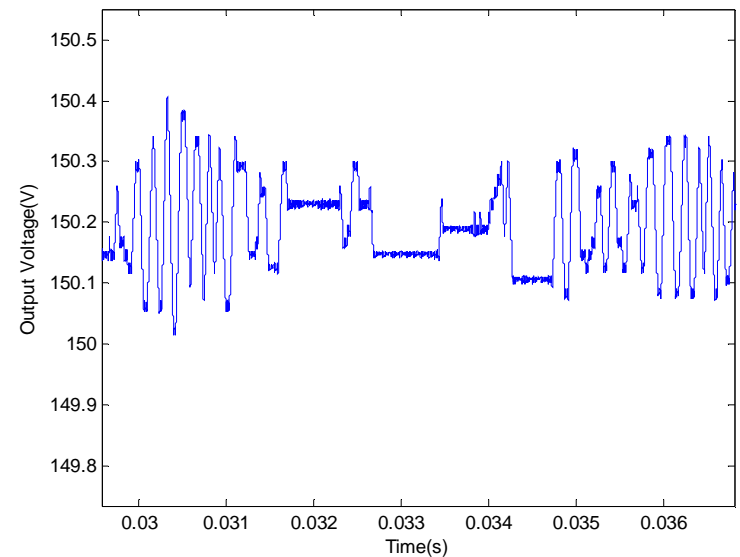

Figure. 5 Output voltage $v(t)$ obtained with the law control $\mathrm{v}_{\mathrm{c} 2}(\mathrm{t})$ of (5), and with the parameters $\mathrm{c}_{2}=8$ and $\mathrm{w}_{2}=300 \mathrm{rad} / \mathrm{V}$ ( $380 \mathrm{mV}$ ripple).

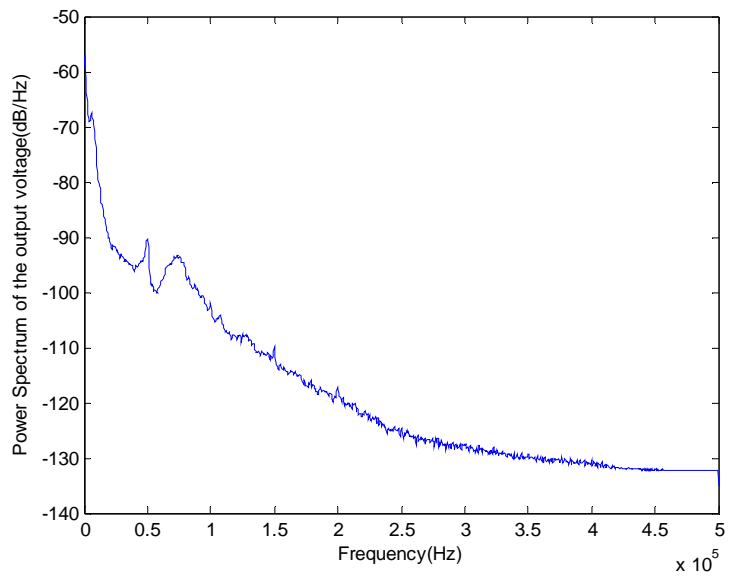

Figure. 6 Power spectrum of the output voltage $\mathrm{v}(\mathrm{t})$ with the law control $\mathrm{v}_{\mathrm{c} 2}(\mathrm{t})$ of (5) $\left(\mathrm{c}_{2}=8\right.$ and $\left.\mathrm{w}_{2}=300 \mathrm{rad} / \mathrm{V}\right)$.

Now, we are interested in a large variation of the parameter $\mathrm{c}_{2}$ until fig. 7 showing a ripple is $11 \mathrm{mV}$ ripples. In this case, $\mathrm{v}_{\mathrm{c} 2}(\mathrm{t})$ presents a better spectrum in fig.8, while ripple of performance and time $\mathrm{v}(\mathrm{t})$ is maintained low.

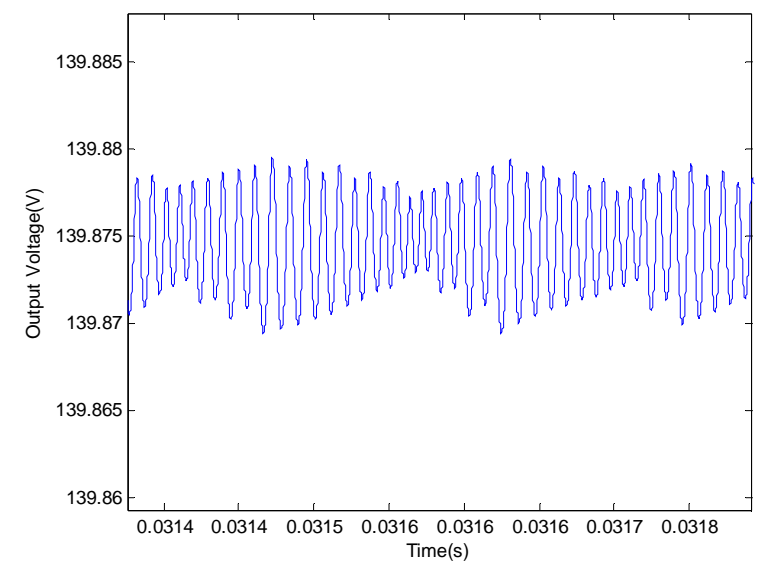

Figure. 7 Output voltage $v(t)$ obtained with the law control $v_{\mathrm{c} 2}(\mathrm{t})$ of (5), and with the parameters $c_{2}=160$ and $\mathrm{w}_{2}=50 \mathrm{rad} / \mathrm{V}$ (11 $\mathrm{mV}$ ripple). 


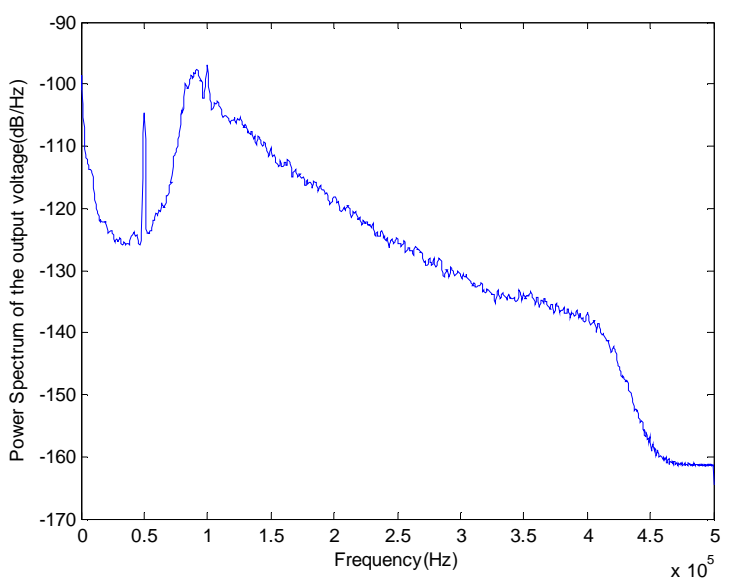

Figure. 8 Power spectrum of the output voltage $v(t)$ with the law control $v_{\mathrm{c} 2}(t)$ of (5) $\left(c_{2}=160\right.$ and $\left.\mathrm{w}_{2}=50 \mathrm{rad} / \mathrm{V}\right)$.

Fig. 9 presents the output voltage ripple in function of the anticontrol parameters $\mathrm{c}_{2}$ and $\mathrm{w}_{2}$. This ripple falls to very small values for a wide domain of low $\mathrm{w}_{2}$ angular frequencies and for high $\mathrm{c}_{2}$ amplitudes. For a better visualization of the small ripple domain, we project 3D space of coordinates $\left(\mathrm{C}_{2}, \mathrm{w}_{2}\right)$ and ripple on 2D as represented in fig. 10.The low ripple area (the black area on the right) can then be identified. Every point $\left(c_{2}, w_{2}\right)$ inside of this area is characterized by a small output voltage ripple dependent of the initial conditions (using $\mathrm{v}_{\mathrm{c} 2}(\mathrm{t})$ with large amplitude of $c_{2}$. Fig. 10 presents on gray area: every point $\left(c_{2}, w_{2}\right)$ inside of this area is characterized by an important output voltage ripple.

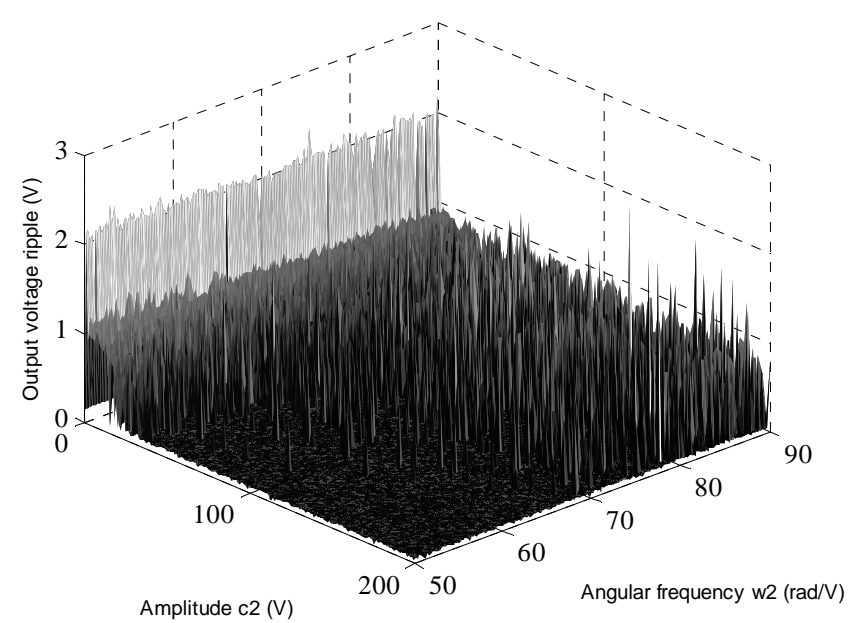

Figure. 9 Output voltage ripple in function of $\mathrm{c}_{2}$ and $\mathrm{w}_{2}$.

\section{CONCLUSION}

In this paper, we apply a new nonlinear feedback controller to a DC/DC buck converter in order to demonstrate that chaos improves power supplies EMC without using EMI filters. On the other hand, this controller maintains a small ripple in the output if we choose a suitable coefficient (large amplitude of c2).

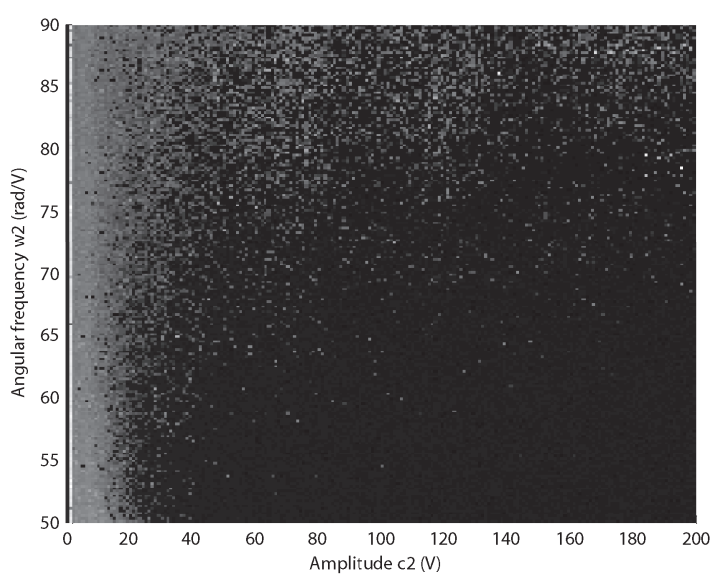

Figure. 10 Plane projection 2D of the 3D space of coordinates $\left(\mathrm{C}_{2}, \mathrm{w}_{2}\right)$ and ripple.

Using Simulink, the simulation results demonstrate that a reduction of spectral peak and consequent spreading of the spectrum can be shown. The output ripple voltage is also decreased.

\section{REFERENCES}

[1] M. H. Chew, "Handling EMI in Switching Mode Power Supply Design, ”Application Note No: N1695D, On Semiconductor (http:/onsemi.com).

[2] F. L. Lin and D. Y. Chen, "Reduction of Power Supply EMI Emission by switching Frequency Modulation, " IEEE Transactions on Power Electronics, Trans. Power Electron, vol. 9, pp. 132-137, January 1994.

[3] A. M. Stankovic, G. C. Verghese and D. J. Perreault, “Analysis and Synthesis of Randomized Modulation Schemes for Power Converters, ”IEEE Trans. on Power Electron., vol. 10, pp. 680-693, July 1999.

[4] J. H. B. Deane, P. Ashwin, D. C. Hamill and D. J. Jefferies, "Calculation of the Periodic Spectral components in a chaotic DC-Dc Converter," IEEE Trans. Circuits and sys. I, vol. 46, pp. 1313-1319, November 1999.

[5] S. Banerjee, A.L. Baranovski, J. L. R. Marrero, and O. Woywode, "Minimizing electromagnetic interference problems with chaos, " IEICE trans. on fundamentals, E87-A(8):2100, August 2004.

[6] V.In, S. E. Mann, W. L. Spano, "Experimental Maintainance of Chaos, ” Physical Rewiew Letters, vol.74, pp. 1129-1142, 1995.

[7] H. Cao, X. Chi and G. Chen, "Suppressing or Inducing Chaos, ” Physical Review Letters, pp. 4420-4423, 2003.

[8] X. F. Wang and G. Chen, "Chaotifying a stable map via smooth smallamplitude high-frequency feedback control, ” Int. J. Circuit Theor. Appl., vol. 28, pp. 305-312, June 2000.

[9] X. F. Wang, G. Chen and K. F. Man, "Making a continuous-time minimum-phase system chaotic by using time-delay feedback, ” IEEE Trans. Circuits Syst. I: Fund.Theor. Appl., vol. 48, pp. 641-645, August 2002.

[10] G. Chen and D. Lai, "Making a dynamical system chaotic: Feedback control of Lyapunov exponents for discrete-time dynamical systems, " IEEE Trans. Circuits Syst. I: Fund. Theor. Appl.,vol 44 , pp. 250-253, 1997.

[11] C. Morel, M. Bourcerie, F. Chapeau -Blondeau, "Improvement of power supply electromagnetic compatibility by extension of chaos anticontrol; " Journal of Circuits, Systems, and Computers; vol.14, pp. 757-770, August 2005.

[12] C. Morel, R. Vlad, J. Y. Morel, “Anticontrol of Chaos Reduces Spectral Emissions, ” Journal of Computational and Nonlinear Dynamics, vol. 3, pp. 1555-142, october 2008. 